\section{PROYECTOS, LENGUAJE E INSTITUCIONES PROYECTORAS*}

\section{BRIAN THOMSON}

A rquitecto, U BA, 1962; M aster en Desarrollo U rbano y R egional, U niversity of C entral England, Birmingham, 1965; Profesor titular de la U niversidad $\mathrm{N}$ acional del N ordeste, 1966-1972; Gerente de Proyecto de la OEA, Brasil, 1973-1974; Director de la Carrera de G eografía de la U BA, 1974; Director del Instituto de Servicios para el Ordenamiento Territorial, Rectorado, U BA, 1974; consultor FLACSO, U NEP, U N ESC 0 FA O, 1975-1976; investigador visitante del Instituto de C iencias Social es de La H aya, $\mathrm{H}$ olanda, 1976; funcionario de U NESCO, París, 1977; funcionario de OEA, W ashington, 1978-1985; Subsecretario de R eforma Administrativa, Secretaría de la Función Pública, Gobierno N acional,1986-1989; funcionario del Banco Interamericano de Desarrollo (BID), W ashington, 1990-1999. Actualmente consultor en metodologías de diseño, gerencia y evaluación de proyectos de desarrollo. Residente en Bethesda, M aryland, USA. Email brian.a.thomson@verizon.net teléfono/fax (301) 365-6671

Cuaderno Urbano N 6, pp. 221-250, Resistencia, Argentina, Diciembre 2007
(*) Glosario: (i) Cartesiano: concepto que uso para este trabajo como tropo para englobar la descendencia técnica y conceptual de una forma de racionalidad geométrica que termina en Gaspard Monge y su geometría descriptiva. Este tropo lo extiendo también para designar el impacto de la geometría descriptiva sobre el lenguaje proyectual de la arquitectura y sus efectos, en otras dimensiones también ocupadas por la arquitectura, donde el método genera resultados constrictivos $y$ limitantes (lo urbano, lo regional, la arquitectura como bien social); (ii) Institución

Proyectora: término que uso para significar toda institución, internacional, nacional, pública o privada, cuya misión es la formulación, ejecución y evaluación de proyectos con objetivos (que deberían ser éticos) dirigidos al desarrollo económico, social, técnico y cultural; (iii) Método Dialógico: método que propongo en este trabajo, derivado de la metodología llamada "del marco lógico" pero que intenta transformar a esta de manera que se enriquezca con principios gramaticales y discursivos cuyo desarrollo elaboro en este trabajo. Los instrumentos son los mismos que los del llamado marco lógico, pero insertos en un contexto ético y textual que respeta el decir del otro en un ámbito transaccional y discursivo ordenado por las reglas de un sistema de juego de palabras.(Continúa en pag.222) 


\section{CUADERNO}

PROYECTOS, LENGUAJE E INSTITUCIONES PROYECTORAS

Desde el punto de vista instrumental propongo seguir utilizando los dos conjuntos de instrumentos que contribuyen por un lado a la definición del universo problema de la comunidad discursiva $y$, por el otro, a la estructuración del universo
ecto de esa misma comunidad proyecto de esa misma comunidad
discursiva. Se trata entonces de un primer "proceso inductivo" de definición del "texto demanda" $y$ de un segundo "proceso deductivo" o estructuración del "texto oferta”. En el primer proceso se incluyen el Análisis de

Involucrados y el Árbol de Pro-

blemas y en el segundo el Árbol de Soluciones, el Árbol de Objetivos, el Análisis de Conflictos Potenciales entre (personas, grupos, instituciones, comunidades, etc. con intereses vinculados al universo problema en discusión) y e

Marco Lógico propiamente dicho. Este conjunto de instrumentos $y$ procesos es recontextualizado, a través de los principios que expongo en este trabajo, como Método Dialógico.

\section{Resumen}

Este trabajo es una reflexión sobre los límites y los horizontes "arquitecturales" de una experiencia. No pretende convencer sino invitar a los colegas a considerar concepciones quizás no ortodoxas del ser y del quehacer de arquitecto. No pretende tampoco reflejar un resultado sino describir un camino personal entre la dimensión unitaria y la dimensión multitudinaria de ese ser y quehacer. El camino recorrido desde ser arquitecto, en mi origen metodológico, unitario (el "mueble", el "edificio"), asentado en los límites de un método cartesiano (la geometría descriptiva), hasta ser arquitecto en dimensiones multitudinarias (Io "urbano", lo "regional", las "instituciones proyectoras") me enfrentó con problemas de diseño que mellevaron cada vez más lejos de lo que el método cartesiano me permitía concebir, diseñar y ejecutar. El quehacer de ser arquitecto de lo multitudinario me ubicó en el campo de la articulación y procesamiento institucional de la relación entre necesidades y soluciones a través del diseño de un proyecto. $M$ is limitaciones cartesianas en este medio me dirigieron a la búsqueda del diseño dentro de un contexto social e institucional, donde encontré en la comunicación lógica un punto de partida, que no era lo visual sino el habla, texto, lenguaje, discurso de los involucrados en un problema (mas o menos sometidos por esquemas de poder), que buscaban posibles soluciones. Inserto, en consecuencia, en el campo de lo institucional, la búsqueda que describo aquí se dirigió hacia el encuentro con lo que inicialmente fue una intuición: la arquitectura del lenguaje que se materializa en el cotidiano de las instituciones. El resultado del camino que aquí describo me lleva finalmente a sugerir a mis colegas que la impronta cartesiana original de la arquitectura que supimos conseguir debe ser - en un mundo donde el diseño, ejecución y evaluación de proyectos es para clientes cada vez más multitudinarios- complementada con una arquitectura del lenguaje y sus reglas, aplicables tanto en el campo de lo metodológico proyectual como en el didáctico de las escuelas de arquitectura; pero lejos de la definición del Diccionario de la Real Academia: "Arte de proyectar y construir edificios". 


\section{Brian Thomson}

PROYECTOS, LENGUAJE E INSTITUCIONES PROYECTORAS

\section{IINTRODUCCIÓN A LA AVENTURA DE UN CURIOSO IM PERTINENTE ${ }^{1}$}

Este ensayo es resultado de una presentación que hice en una conferencia pronunciada en la Facultad de Arquitectura del la U N NE en agosto de 2006 y su referencia, una descripción de hace algunos años de mi experiencia personal como arquitecto, inserto en un institución proyectora (ver referencia 1, Glosario). En esa conferencia, esbocé esa experiencia para conciliar mi formación con el hecho de trabajar en circunstancias institucionales que la desbordaban. Este escrito es un intento de llevar ese esbozo a una exposición más ordenada y útil para mis colegas.

Los resultados de la experiencia mencionada no emergieron de una inspiración creativa sino de un enfrentamiento cotidiano con lo que años después pude definir como una sensación de desborde, como un desfase conceptual, que resumí, en el tiempo, como un problema de dos lenguajes. U no, el de la arquitectura en su momento de proyectar, dominado por una descendencia cartesiana, el método de la geometría descriptiva de M onge. Otro, el de una institución proyectora, expresado en hablas transformadas en formas textuales dominadas por reglas también de cepas cartesianas, la racionalidad gestionaria. La primera indicaba los límites de un método que habíamos extendido a campos ( planeamiento urbano y regional) para los cuales sólo servía como apoyo analítico pero no como instrumento heurístico. La segunda reflejaba mi inmersión en un mundo supuesto como conocido, porque siempre hemos funcionado en instituciones, pero desconocido desde la perspectiva del diseño de proyectos dentro de ellas.

Esta inserción en una institución proyectora introdujo en mi problemática la dimensión del poder, expresado como lenguajes rígidos que se me manifestaban técnica y éticamente hostiles. La hostilidad interpersonal, de origen profesional, se expresaba en la arrogancia narrativa de los "profesionales" cuyaterminología no sólo no aceptaba un enfoque de diálogo transaccional, sino que además distorsionaba la demanda de los supuestos beneficiarios de los productos de la institución proyectora al "traducir"sus requerimientos en textos referidos a modelos conceptuales predeterminados. La otra hostilidad lingüística se originaba en las terminologías cuasi-técnicas adoptadas en las áreas decisorias de la institución proyectora como expresiones de las Ilamadas políticas de desarrollo y sus sucesivas transformaciones dirigidas a diferentes intereses transformadores delas llamadas rigideces económicas, contrarias a la operación fluida del mercado.
1- Ver encabezamiento del Capítulo XXXIII. El Ingenioso Hidalgo Don Quijote de la Mancha, Cervantes. 


\section{CUADERNOU:and}

PROYECTOS, LENGUAJE E INSTITUCIONES PROYECTORAS

2- Este encuentro, viniendo desde la arquitectura, me llevó a lecturas: del ya citado Deyan

Sudic, de Umberto Eco de Postmodernism and Architecture (Rethinking Architecture a Reader in Cultural Theory, Editor Neil Leach, Ed Rutledge, Londres, 1997 (ver Umberto Eco, pp. 182 a 202, Function and Sign: The Semiotics of Architecture); de Negri, Deleuze, Guattari y otros sobre la importancia del nuevo fenómeno de la multitud y de diseño para la multitud; y de Slavoj Zizek (Rethinking Marxism, Routledge, Volumen

19, numero 1, pp. 46 a 58 ,

Slavoj Zizek "Multitude,

Surplus, and Envy”) quien en sus últimos escritos, partiendo

de Michael Hardt y Antonio Negri hace referencia a que en

el neoliberalismo actual la producción de relaciones sociales es el verdadero objeto de la producción, incluyendo la producción del espacio para esas relaciones sociales.
En esta situación, y siendo jefe del área de metodología de diseño de proyectos, abogué por la introducción del Ilamado marco lógico que ofrecía, a la luz de los dilemas identificados, dos ventajas. Por un lado creaba algún orden en el discurso profesional, y por el otro introducía la dimensión del lenguaje institucional en un cauce que permitía compartir conceptos profesionales en un diálogo más amplio a través de ciertas reglas. Pero si bien a nivel profesional obtuve al gunas respuestas animadoras, no contaba con la hostilidad institucional que se originaba en la aceptación a regañadientes del uso de nuevos métodos, como el marco lógico, sólo porque se exigía su uso desde los países donantes para responder a la nueva demanda internacional de responsabilidad institucional (hoy definida como responsabilidad), y no porque mejoraría el diseño y ejecución de proyectos. En realidad el rechazo de la conducción institucional a esta metodología era porque reducía su capacidad y la de sus "profesionales" de usar textos (lenguaje) tecnicistas para oscurecer la realidad y reducir sus responsabilidades finales ante sus eventuales clientes. Las cepas cartesianas, la racionalidad gestionaria, otra forma de geometría descriptiva, volvió a aparecer en la forma de reducir el marco lógico a una tabla dependiente en su estructuración de la tabla de costos del proyecto, proceso que se ha reproducido en múltiples instituciones proyectoras internacionales.

Si bien podía entender las causas políticas y de poder que llevaban a esta situación, mi problemática era tratar de explicármel as de tal manera que pudiera contribuir a la defensa de la verdad de los supuestos clientes de estas instituciones. Con el tiempo, esta búsqueda me llevó al encuentro ${ }^{2}$ con el último trabajo, en parte póstumo, de Ludwig W ittgenstein, "Philosophical Investigations". Este trabajo, que se aparta de los complejos conceptos lógicos del Tratactus Lógico-Philosophicus de su juventud, esencial mente fue escrito en la década de 1940, y publicado en 1953, como su propia autocrítica y su intento de acercar sus pensamientos sobre el lenguaje filosófico al lenguaje cotidiano de la gente y a las reglas de la gramática.

La noción fundamental y - para mí- transformadora de W ittgenstein es que todo lenguaje tiene su contexto institucional, o de comunidad humana, y toda institución crea su propio "juego lingüístico" o "juego de palabras". U n juego muy serio dado que por medio de él toda institución/comunidad humana construye un código lingüístico que asocia lo que se dice con la realidad objetiva externa a ese decir. N ada puede ser más relevante 


\section{Brian Thomson}

PROYECTOS, LENGUAJE E INSTITUCIONES PROYECTORAS

para la noción de proyecto o más genéricamente para la noción de la arquitectura organizacional y gestionaria que determina ese diseño, cuyo objeto debía ser la construcción de un puente entre deseo y realidad, y no la generación de tropos ${ }^{3}$ que permiten deslizar ${ }^{4}$ contenidos diferentes a los reales, a través de cadenas significativas aparentemente real es pero en efecto figuradas.

\section{LENGUAJES, AUTORIDAD Y PROYECTOS}

Aquí describo la tendencia de las instituciones proyectoras y sus profesionales "proyectores" de transformarse en sus propias Torres de Babel, y analizo las consecuencias de la tendencia a diluir y cambiar el sentido del lenguaje de los otros, perdiendo éste su contenido ético original, lo que implica no respetar sus expresas necesidades.

\subsection{La Torre de Babel y los lenguajes}

Como suponemos que todos hablamos el mismo idioma (castellano, inglés, etc.) no tomamos suficientemente en cuenta a lo que lingüistas y lógicos ( $p$. ej. Sausurre, Chomsky, W ittgenstein), llaman los diferentes géneros o juegos de palabras, o sea las formas socialmente condicionadas, por la cultura del sujeto y su entorno de relaciones sociales, con las cuales usamos nuestros idiomas, nuestras partes de la Torre de Babel. Es más, toda institución dirigida hacia la producción y ejecución de proyectos, es su propia T orre de Babel, ya que sus idiomas cambian internamente según la situación (reunión de trabajo de equipo de proyecto, comités de administración media, comités de alta administración, comités de directorio) y el juego de palabras que implica. El mayor problema ético para un proyector en estas circunstancias es tratar de proteger el texto original dela demanda de los beneficiarios, de la erosión de significaciones emergentes de tales géneros o juegos. Sin este cuidado, la significación original de los textos se deslizará, adoptando significados diferentes para cada situación interna, generando respuestas proyectuales que están lejos de la demanda inicial.
3- Diccionario de la Real Academia, Decimonovena Edición, Madrid 1970: "Empleo de las palabras en sentido distinto del que propiamente les corresponde..."

4- Ver Jacques Lacan y su concepto del "glisser", o "glissement", el deslizar o deslizarse de las palabras hasta que pierden su valor $y$ contenido significante original. 


\section{CUADERNO}

PROYECTOS, LENGUAJE E INSTITUCIONES PROYECTORAS

\subsection{La parábola de Sw ift y los proyectores}

En su obra Los Viajes de Gulliver, Jonathan Sw ift relata el cuento de un reino en el cual el rey y su corte vivían en una isla que flotaba sobre los dominios del rey. Este era bondadoso, y cuando pasaba sobre una al dea tiraba regal os a los pobladores junto con sus cortesanos. El rey era asesorado por un grupo de sabios a quienes Sw ift llamó "proyectors" (proyectores), o sea especial istas en hacer proyectos. Pero estos proyectores le traían problemas al rey porque muchos proyectos se contradecían entre sí, y esto era porque cada proyector trabajaba en un cubículo aislado de los demás proyectores con quienes no se comunicaba. Esta parábola, en el caso de Swift de intencionada crítica política, exagera de manera jocosa lo que ocurre en una institución proyectora cuando no hay comunicaciones adecuadas ni referentes universales. Cada propuesta es un universo lingüístico y resulta, por ello, muy difícil sostener una gestión de conjunto. No porque no se quiera hacer, sino porque la natural eza de cada unidad proyectora se parece a una mónada de Leibniz. Si una institución proyectora aprobara un proyecto por año la gestión sería fácil. Cuando aprueba 80 por año y esto resulta en una cartera de 400 proyectos en ejecución (la gestión de un gobierno por ejemplo), decir que se administran como un conjunto no es lo mismo a que sea así. Solo se podrá hacer si se construyen con al gunas características comunes que faciliten el seguimiento de la ejecución de grandes números de proyectos. Para esto se necesitan lenguajes comunes entre proyectores, y se requiere que se introduzcan en los procesos de diseño, ejecución y evaluación, referentes discursivos que surjan de un juego de palabras compartido.

\subsection{Dialogismo y la dimensión de la autoridad}

Desde la perspectiva de una institución proyectora debemos ahora agregar al concepto de $W$ ittgenstein (que el lenguaje es esencialmente producto de lo que un cierto grupo humano considera palabras, significantes, y cadenas de palabras, significados), la noción de la jerarquía, autoridad y/o poder que está detrás de todo significante y sus significados, y considerar quiénes otorgan ese poder a los dichos/relatos/textos, por su posición en una jerarquía de decisiones y/o, por su posición, en una jerarquía de profesiones (Ios que "profesan" creer en ciertos significad os y no en otros). 


\section{Brian Thomson}

PROYECTOS, LENGUAJE E INSTITUCIONES PROYECTORAS

Para ayudarnos a entender la dimensión de la autoridad en las instituciones, propongo introducir las ideas de dos lingüistas rusos, quienes enriquecieron el concepto de "juego de palabras" de W ittgenstein con los conceptos del diálogo y de la autoridad, comunes a toda comunidad institucional. M e refiero a M ikhail Bakhtin y a Valentín Volosinov.

A mbos sufrieron a nivel académico las persecuciones estalinistas por la significación que tuvieron sus revelaciones sobre el contenido de relaciones de diálogo y autoridad implícitas en todo lenguaje. Sus refl exiones tienen hoy mucho que ver con las nociones desarroIladas por Gilles Deleuze y Antonio Guattari sobre las relaciones multimodales y multipolares propias del discurso social. ${ }^{5}$

Bakhtin desarrolló los principios del "dialogismo", es decir de la "multivocalidad", en los intercambios verbales dentro de una comunidad y entre comunidades. Este lingüista se rebeló contra los principios formal istas - aunque avanzados para su época - que había expuesto Saussurre (y sus seguidores desde principios del siglo XX), por considerarlos vacíos de contexto. Para ello, Bakhtin introdujo precisamente el concepto de contexto en sus investigaciones lingüísticas, lo cual lo llevó a considerar que los dichos de todo "hablante" siempre se dirigían a algún otro hablante, quien le debía responder ( hasta con su silencio).

De ello dedujo su principio de "dialogismo" que plasmó en su obra La Imaginación Dialógica. En esencia, este punto de partida relativizó la significación de todo discurso porque señal aba que los significantes, y los significados construidos con ellos, adquirían un valor cambiante según el contex to de su uso. Ello llevó a Bakhtin a sugerir el concepto de que toda comunidad lingüística, y más aún toda comunicación dentro y entre comunidades lingüísticas, está fundada en el principio de la "heteroglosía". O sea esencialmente que cada habla parte de su propio glosario. Para Bakhtin la dialogización de estos hablas, es decir, su confrontación y glosa ordenada permitirían que una mala comunicación heteroglosa se fuera transformando, por la vía de su dialogización, en una buena comunicación, a la que él Ilamó "homoglosa". Agregando que tal "homoglosía" o diálogo convergente puede resultar de un acto transaccional abierto entre los participantes 0 , en el contexto de una institución verticalizada, ser una homoglosía forzada desde las jerarquías de la institución.
5- Estos autores desarrollan la noción de rizoma (propia de los pastos) como sustento de una interpretación de la sociedad más horizontal y más descentrada, en oposición a la estructura de raíz, propia de los modelos interpretativos jerárquicos y arborescentes de las estructuras sociales. 


\section{CUADERNO}

PROYECTOS, LENGUAJE E INSTITUCIONES PROYECTORAS

Estas formulaciones me ayudaron a comprender la circunstancia institucional en la cual me encontraba y a su vez me permitieron entender que el llamado marco lógico era una visión mochada, originada en genes cartesianos, de una parte de lo que en realidad era una forma de "método dialógico". Desde este concepto, también pude entender el proceso de diseño y ejecución de un proyecto como una realidad lingüística y expresión directa de la realidad social, que nos permite pasar de un estado de heteroglosía a un estado de homoglosía transformador del texto heteroglósico original pero respetando las condiciones contextuales que generaron ese texto original. Ello permitiría afirmar que estas transformaciones, sin soluciones de continuidad, entre habla/texto demanda y habla/texto oferta sólo son posibles si se aplica un método que permita dialogizar el discurso inicialmente heterogloso durante el proceso de diseño generando un habla/texto homogloso facilitador de la ejecución y evaluación de un proyecto.

Pero esta conclusión es lamentablemente sólo parcial, porque se desarrolla únicamente el interior del ser proyecto y deja de lado el contexto comunicacional de la institución proyectora que contiene relaciones de autoridad. Por más que rechacemos formal mente esta realidad, por razones éticas y moral es, hay asimetrías de autoridad entre una institución poderosa y sus contrapartes y/o clientes, entre miembros de equipos de proyecto, entre el equipo de proyecto y las diversas y heteroglosas subcomunidades lingüísticas al interior de toda institución. Esta problemática comenzó a aclararse a partir de mis lecturas de Volosinov, con las cuales pude completar mi entendimiento de mi circunstancia institucional. Este lingüista, en función de la noción del poder y la autoridad de cada participante en un proceso dialógico, introduce los conceptos de "procesos organizativos" y "actividades constitutivas" que son previos al proceso dialógico y estructurantes del mismo en una institución proyectora. Estos dos conceptos llevan a plantear cuáles son esos procesos organizativos" en una institución proyectora que a su vez conducen a las "actividades constitutivas", y de allí tratar de definir en qué medida facilitan o no la continuidad de los procesos dialógicos en su seno. Como ejemplo, no necesitamos ir más lejos que las reformas administrativas impuestas, desde las instituciones proyectoras, a nuestros países en la década del ' 90 , donde se modificaron sustancialmente los procesos organizativos y las "actividades constitutivas" de las instituciones del estado sin tomar en cuenta, desdela perspectiva del recurso fundamental de la institución, los funcionarios y sus lenguajes, los efectos que tales cambios tendrían sobre la posibilidad de mantener 


\section{Brian Thomson}

PROYECTOS, LENGUAJE E INSTITUCIONES PROYECTORAS

un proceso dialógico, o de dialogización, externa e interna; dejando de lado también los discursos y textos, demanda de la sociedad.

Con razón que más allá de voluntades personales, y de bien intencionadas declaraciones ejecutivas respecto de la utilización del marco lógico, en la cultura discursiva de la institución proyectora este instrumento y su peligroso trasfondo dialógico, se consideró básicamente una molesta tabla más, anexa a los documentos de proyecto. Esa cultura no permitió la aplicación de un método que facilitaría no sólo transformar toda "heteroglosía" en una "homoglosía", a través de las diferentes comunidades y reglas lingüísticas internas de la institución, también impidió cambiar la centralidad del discurso de la autoridad estructural, y el discurso de la autoridad de los instrumentos económicos y financieros, por una centralidad basada en la demanda humana y en el desarrollo como concepto verdaderamente integral de inducir cambios adecuados (Spinoza, ver párrafo 3.2) en una comunidad. Esta conclusión también se extiende a la falsa introducción de temas como la participación, o la idea de que las instituciones son tolerantes y neutral es "procesadoras de conocimiento", o la idea de "indicadores de desempeño", etc., todas las cuales se encontraron con los embates de una homoglosía impuesta desde la autoridad.

Después de un análisis de casos que desarrollé en la institución proyectora ${ }^{6}$ concluí que el rico bosque de un incipiente método dialógico no se podía ver por la presencia del gran árbol de la autoridad implícito en las fórmulas verbales y escritas aceptables de la institución. Esto, además, revela que el principio de la solución a la práctica de generar homoglosías forzadas de las instituciones proyectoras no se encuentra solamente en sus políticas y procesos gestionarios, como generalmente se ha supuesto desde la dimensión política contestataria, pero también fundamentalmente en cómo la institución ordena, en formas comunicacionales, los contenidos discursivos de esas políticas y procesos.

\section{DISCURSO,PROYECTOSY EL MÉTODO DIALÓGICO}

En este apartado, abordo el tema del discurso y su tergiversación en las Torres de Babel de las instituciones proyectoras, haciendo referencia a los pensamientos de U mberto Eco sobre la Torre de Babel y enfatizando el tema ético spinoziano de los discursos adecuados e inadecuados y su relación con la manera en que se describen los objetivos y contenidos de los proyectos formulados por las mencionadas instituciones.
6- El autor pone a disposición del lector, a través de EUDENE, los siguientes casos; (i) Caso Villahermosa: un árbol de problemas bien desarrollado, puede ser la base para la formulación de un plan estratégico si en el análisis que efectuamos incluimos a los involucrados y a los datos que caracterizan sus intereses y sus mandatos y recursos. En este sentido, el caso de Villahermosa se presta a constituir un modelo para la discusión grupal de los problemas de desarrollo de nuestras ciudades, al dirigir la discusión hacia el campo de los problemas en sí, y evitando la usual caída en los debates técnicos basados en paradigmas interpretativos enfrentados; (ii) El Plan Fénix: demuestra cómo el uso del método dialógico permite transformar una propuesta de políticas en algo más parecido a un programa; (ii) Kirchner, Pangloss y Kraus:

transformación de un discurso político en un programa; (iv) Barrios: ejemplo del uso del método para definir los objetivos de un programa respetando la heteroglosía inicial de los múltiples participantes; (v) Síntesis Metodológica. Otros documentos/casos pueden ser puestos a disposición de serme solicitados. 


\section{CUADERNO}

PROYECTOS, LENGUAJE E INSTITUCIONES PROYECTORAS

7- Ver Umberto Eco, Serendipities-Language and Lunacy, Columbia University Press, 1998.

\subsection{La distorsión del discurso}

La búsqueda de una forma de comunicación liberadora y unificadora al mismo tiempo, la encontramos en las reflexiones y en el pensamiento de U mberto Eco. En su obra "Serendipities"7 traza las dificultades y caminos erróneos ocurridos en la búsqueda de un lenguaje universal que salvara al hombre de la incomprensión y del conflicto. Eco desarrolla la noción de la búsqueda de un idioma, de un lenguaje, que saque a la humanidad de la trampa de la Torre de Babel. Nos describe el valor narrativo del discurso pero al mismo tiempo nos alerta sobre su capacidad de distorsión y nos dirige hacia el único criterio de verdad que en el fondo radica en la sabiduría de la comunidad que debe siempre ser consciente de la falibilidad de su conocimiento. Pero en el campo específico del lenguaje Eco describe la problematicidad de la relación entre nombres y cosas que se resuelve bíblicamente de una manera extraña. La Biblia relata que Dios no le nombra las cosas a Adán, sino que deja que Adán las nombre, pero para evitar la posible confusión entre nombres y cosas, le otorga a Adán una facultad particularmente humana: un conjunto de princi pios para una gramática universal. Quizás esta sea la inspiración indirecta para los famosos "a prioris" de Kant y el concepto de estructura lingüística ex-ante que planteó Noam Chomsky. Asumir entonces el valor de este conjunto de principios sería para una institución proyectora no una forma de escapar de la Torre de Babel, pero sí por lo menos de escapar de su propia "homoglosía" forzada que esconde la heteroglosía proveniente de la demanda de sus clientes.

Pero, en este último caso pareciera que las prácticas de la institución establecidas en sus "procesos organizativos" y "actividades constitutivas", la distancian de los principios de una lógica gramatical universal. En esto las instituciones proyectoras parecen persistir en creer que el lenguaje originario perdido de Adán está en los nombres de las cosas y no en los principios del nominalismo y la gramática. Es más, no sólo creen en esto sino que se dedican a crear nombres para cosas de manera realista que supone la existencia objetiva de los términos que crean y transmiten a sus funcionarios y clientes. Vale la pena también recordar, por sus derivaciones epistemológicas - implícitas en muchas profesiones- , que Eco en su trabajo también se refiere a otro predecesor importante del concepto de la lógica del lenguaje y su significado nominal. Se trata de Leibniz, que en el marco del debate lingüístico heredado, ya no buscaba la utopía de un lenguaje universal - que 


\section{Brian Thomson}

PROYECTOS, LENGUAJE E INSTITUCIONES PROYECTORAS

había obsesionado al mundo escolástico y renacentista - y creyó hallar la solución a la universalidad en la búsqueda de un lenguaje matemático que sirviera para racionalizar nuestros dichos. Esta rica línea de pensamiento después de un largo decurso termina en la lógica formal, tal como la conocemos hoy, y su desarrollo en la noción (y aplicación práctica en cibernética) del hipertexto. Pero también lo encontramos hábilmente distorsionado en al gunas formulaciones económicas y sociales, excesivamente abstractas y formales, que disocian el modo de ser de lo que analizan y le asignan un modo de ser nuevo a través del contenido significante de los nombres que manipulan, robándole a la comunidad su juego de palabras.

\subsection{El discurso adecuado}

Claramente un visionario (hoy nuevamente reconocido), en el campo de la crítica de la manipulación discursiva que acabo de señalar, Spinoza también es pertinente a nuestro tema, pues distinguió entre pensamientos (y obviamente sus expresiones lingüísticas) "inadecuados" y "adecuados". Los primeros no nos indican su proceso de producción, su causa. Los segundos se caracterizan precisamente por hacerlo. En este sentido podríamos derivar la noción de que un proyecto "adecuado" es aquel que nos describe cómo una determinada realidad debe ser producida porque no sólo nos describe la genealogía de sus el ementos constitutivos, sino también nos indica cómo puede ser alterado y adaptado a la realidad cambiante, gracias a la descripción de los eventos cotidianos y prácticos de su proceso de producción. ${ }^{8}$ Ello requiere que el proceso de producción de un proyecto adecuado también sea adecuado, es decir, dialógico. Si no, lo que tendremos es un "producto proyecto" desarticulado que por esa misma esencia en vez de ser un instrumento de articulación social (objetivo del desarrollo) se transforma en un instrumento de la desarticulación social. ${ }^{9}$

Estas consideraciones permiten afirmar que tales apartamientos entre realidad y discurso, en los dichos, tanto llanos como informados, de una institución proyectora, pueden reconocerse, si se parte del concepto contextual implícito en la noción de "juegos de palabras", que W ittgenstein usó para rescatar al lenguaje cotidiano de las trampas que le habían preparado los positivistas lógicos (también descendientes cartesianos). Aplicando estos conceptos derivados de la noción de "juegos de palabras" y asumiendo los $\overline{\text { 8- Ver Jason Read, Biopolitical }}$ Production.

9- Ver John Holloway, Change The World Without Taking Power, Pluto Press, 2002. 


\section{CUADERNO}

PROYECTOS, LENGUAJE E INSTITUCIONES PROYECTORAS

limites del marco de una institución proyectora,, me atrevo a sugerir que lo que he denominado aquí "método dialógico", es una estructura sintáctica y semántica (ver 5.6) que nos permite ordenar la relación problemas/soluciones para que se pueda diseñar, gerenciar y evaluar un proyecto, colocando las palabras, las personas, los objetos y las acciones, en un sistema de cadenas de significación pertinente al orden que requiere la particular forma de ser de un "proyecto adecuado".

\subsection{Los límites del modo de ser proyecto y el juego lingüístico}

Los conceptos precedentes se han referido básicamentea la dimensión institucional denuestra problemática. Propongo ahora aplicarlos más directamente a la noción de proyecto.

En este sentido, un proyecto podría definirse como el producto lingüístico homogloso, emergente de la integración de procesos organizativos y actividades constitutivas concensuados que contiene una síntesis lingüística de acciones a ejecutar en función de una meta. A esta síntesis me atrevo a decir que la podemos encontrar en un marco lógico bien el aborado desde la metodología dialógica que estoy proponiendo. Este instrumento es lingüísticamente una homoglosía producida por la institución proyectora ética para los eventuales beneficiarios que debe haber sido basada en la inicial heteroglosía que surgió originalmente de estos últimos. Esta heteroglosía debe haber sido la materia prima que fue dialogizada a través de los instrumentos de lo que estoy denominando un método dialógico.

Pero, siguiendo a W ittgenstein, un proyecto es sobre todo también un juego lingüístico cuyo objetivo fundamental es desarrollar su propia potencia (lo que contiene como meta implícita en su paquete lingüístico) dentro del contexto el egido para ello. Esa potencia también debe comportarse según ciertas reglas de juego cuyo objeto es limitar su extensión, sin lo cual - valga la aparente contradicción - no se realizaría (no hay potencia sin límites). U n proyecto tiene entonces un conjunto de límites que lo caracterizan en sus formas de ser: un límite de meta, un límite temporal, un límite financiero. Y, tieneademás un conjunto de límites que determinan su forma de estar: generalmente límites en el espacio geográfico y en el contexto sectorial e institucional en el que debe lograrse su potencia a través de su implementación. 


\section{Brian Thomson}

PROYECTOS, LENGUAJE E INSTITUCIONES PROYECTORAS

Este conjunto de límites lleva a considerar que desde la perspectiva de una institución proyectora también debe contemplar los límites de su autoridad o poder, y reconocer los riesgos de suponer que su realismo terminológico inserto en sus proyectos posee más autoridad que la realidad concreta. Parece obvio que una institución está en tierra firme (siempre y cuando se cumplan los supuestos pertinentes) hasta el punto en el cual se generan los productos del proyecto; pero está en tierra menos firme cuando se trata de los pasos que implican los resultados del uso de esos productos por parte de los beneficiarios. Y desde aquí en adelante la institución proyectora y, frecuentemente, la entidad ejecutora están más sujetas a la noción de "esperanza" que a la noción de "potencia", es decir, más sujetas a los supuestos sobre la realidad externa al proyecto sobre la cual no tienen ningún control.

En realidad, entonces, en las instituciones proyectoras generalmente - como hemos sugerido- no sól o se produce una distorsión de la demanda original, sino al mismo tiempo, en pos de sus mandatos políticos, se produce un sobredimensionamiento de los efectos esperados de un proyecto con el cual la dosis de lo que se quisiera que ocurra es mayor que la que es posible que ocurra. La institución proyectora yerra tanto por defecto, al simplificar la demanda social inicial, como por exceso al pretender imponer sus políticas más allá de los límites de lo factible.

F rente a estos errores dimensionales y sus altísimos costos financieros y social es las propias entidades proyectoras ganarían efectividad si pudieran asumir que operan en un campo de juegos de palabras que, siguiendo a W ittgenstein, responden a "formas de vida" que le dan al lenguaje su significación y donde se ligan entre sí lenguaje, cosas, personas y acciones. Asumir este principio para una institución proyectora, incluyendo obviamente a los gobiernos y sus políticas, sería un cambio fundamental, porque aunque la institución se ocupa del valor del lenguaje en cuanto a lo formal/legal, parece olvidarse de darle la misma importancia a lo que W ittgenstein considera fundamental: la relación del lenguaje con el mundo cotidiano.

\subsection{Proyecto y verdad}

El proyecto es también por ello el lugar de realización de los dilemas de lo verdadero y de Io fal so, de lo correcto e incorrecto, y de la diferencia entre la verdad técnica y la verdad 


\section{CUADERNO}

PROYECTOS, LENGUAJE E INSTITUCIONES PROYECTORAS

10- Ver Bourdieu, Pierre, The Logic of Practice, Stanford University Press, California, 1999. práctica de nuestro discurso lingüístico. Con el método dialógico se acaba la posibilidad de la ofuscación entre estos dilemas binarios. En tal sentido el proyecto debe ser la conexión esencial de una institución proyectora con su contexto. Y es en esa conexión donde se prueba la certeza de su discurso en la realidad mejorada de sus beneficiarios. Estos se confirman en la "Iógica de la acción"10 del proyecto: su ejecución.

Vemos así que una institución proyectora es una institución que a través de sus proyectos procesa y realiza su discurso, y que este discurso es la expresión más acabada de su esencia y su existencia, de su actualidad y de su potencialidad. El lenguaje del desarrollo debería tener en esta institución proyectora, como comunidad lingüística prestataria/prestatarios, su punto de realización en el contenido dialógico que debe sintetizar y estructurar ejecutivamente a un proyecto. Tal responsabilidad obliga a recordar que J acques Lacan señaló que las palabras no sólo tienen la posibilidad de comunicar, sino también de matar lo que comunican. Las palabras de los informes de proyectos de una institución proyectora son potenciales armas de doble filo, que pueden construir o destruir el futuro. C abe manejarlas entonces con mucho cuidado. Desde esta perspectiva, W ittgenstein no es sólo inspirador de la idea del método dialógico, también este filósofo colocó el lenguaje como guardián de los valores éticos de lo que decimos, y en consecuencia hacemos. En esta cuestión vital, W ittgenstein se inspiró en Karl Kraus (1874-1936), pensador y periodista austríaco que siempre se dedicó al contenido ético del lenguaje público. Este concepto deW ittgenstein también se utiliza para evitar ser atrapado por debates ideológicos, fáciles y frecuentes cuando se discute sobre instituciones proyectoras, porque aunque se contara con una varita mágica que pudiera cambiar sus actual es políticas, todavía nos quedaríamos con el problema de cuán verdaderos son sus textos desde la perspectiva de logro de los objetivos que cualquier ideología del desarrollo se podría plantear. Karl Kraus criticó a la prensa vienesa de "ahogar a los sustantivos en un mar de adjetivos". Para una institución proyectora esta imagen acuática se invierte porque al mirar las tablas contables que tienen una fuerte influencia sobre el texto descriptivo de los proyectos, observamos que los adjetivos y los verbos (que definen los objetivos) se ahogan en un mar desustantivos (objetos).

\section{PRIN CIPIOSPARA UNA ARQUITECTURA DEL LENGUAJE}

Lo descrito hasta ahora en este ensayo podría asemejarse a la descripción de una tabla de ajedrez. Para avanzar en la superación o conocimiento de los desfases conceptual es seña- 


\section{Brian Thomson}

PROYECTOS, LENGUAJE E INSTITUCIONES PROYECTORAS

Iados hasta aquí, debemos pasar a la consideración de las reglas del ajedrez que trasforman a la tabla en un instrumento lingüístico que define el lenguaje de la comunidad ajedrecística o proyectora. Ello implica comenzar a considerar los instrumentos del método desde una perspectiva distinta a la que se ha aplicado en las instituciones proyectoras que transformaron el marco lógico en otro instrumento cartesiano más. Significa rescatar la esencia de otro paradigma metodológico.

\subsection{0 rdenamiento textual de las demandas de los otros}

Propongo partir ahora de nociones previas a las de la lógica técnica y profesional que constituyen nuestra cultura institucional como profesionales en instituciones proyectoras con la intención de aterrizar en los contenidos que esa cultura tiende a cubrir con un velo cartesiano.

Esto implica partir de otra forma de ver las necesidades o demandas de los "otros", como así también ver cómo el nosotros, proyector profesional e institucional, responde con sus productos u ofertas de soluciones. Es necesario salir de la confusión que genera hablar la misma lengua con diferentes glosarios, o sea juegos de palabras, manejando sintácticas y semánticas diferentes.

Así se producen las distorsiones binarias entre hablas resultantes del diálogo binario de los procesos organizativos y las actividades constitutivas de instituciones proyectoras caracterizadas por establecer las condiciones en las cuales presta 0 entrega recursos a un beneficiario. Estas relaciones binarias demanda-oferta - en todas sus manifestaciones- , que aparecen en diversas combinaciones de procesos y actividades, distorsionan aun más la incomprensión inicial del origen hiperglósico de la demanda. Ello es evidente en la cantidad de reparos que pone una institución proyectora en garantizar al guna homogl osía en el medio de la siempre inminente Babel. Pero, para remarcarlo netamente, esta homoglosía es impuesta por la autoridad y no por un consenso. El contexto de esta problemática tiene una respuesta clara. jir hacia ese lugar que asegura una homoglosía adecuada por la vía de la dialogización y no por la vía de la coerción!Y ese ir reside en utilizar de manera más comprensiva los instrumentos discursivos y textuales. 


\section{CUADERNO}

PROYECTOS, LENGUAJE E INSTITUCIONES PROYECTORAS

11- Todos los practicantes del método, inconscientemente reconocían que se trataba de algo más que el marco lógico, cuando intentaron darle un nombre más englobante que el de una tabla. Sin embargo no pudieron escaparse del universo de las reglas del juego del

proceso de planeamiento y del

ciclo de proyectos, en el cual todos se formaron. Así cayeron

en definiciones relativas a los

productos del método y no en definiciones vinculadas con sus contenidos lingüísticos. La GTZ lo denominó "método ZOPP", o sea "planificación de proyectos en función de objetivos" que, en realidad, no refleja el verdadero contenido del método. Otros, por ejemplo el grupo consultor Team Technologies del área de Washington, le denominan PCM

$o$ "project cycle management (methodology)", o sea "gerencia del ciclo de proyecto", definición que se puede referir a varios paquetes de herramientas para ese fin, pero no precisamente al verdadero contenido único del método dialógico tal como lo estamos considerando aquí.

12- En esta definición planteo el concepto de diseño, en el marco del concepto de proyecto, como toda actividad

independientemente de la etapa en que se lleve a cabo, destinada a organizar recursos para un acción institucional sea de diseño propiamente dicho, sea de ejecución, o sea de evaluación.
No quedando ninguna duda sobre lo importante del ordenamiento discursi vo y textual en todas I as etapas del proceso de diseño-ejecución-evaluación nos queda asumir el reto que nos legara W ittgenstein: en el juego de una institución (ejecución exitosa de proyectos), y en función de los usos del lenguaje, delinear algunas reglas para su manejo, que nos permitan generar textos homoglósicos pero resultantes del consenso emergente de una participación en el universo del lenguaje y no de una coerción de autoridad institucional. Pero para no dejar una coerción y entrar en otra, debemos recordar que en el método dialógico no hay un texto que sea mejor que otro por sus excelencias técnicas, ni tampoco por su aplicación perfecta del método. Lo único que puede ser mejor es que el texto resultante responda a los criterios de verdad y moralidad inherentes al método de W ittgenstein.11

\subsection{El método dialógico desde la perspectiva del tex to y su contexto}

Para penetrar el significado práctico del o que aquí llamo "método dial ógico de diseño"12 es fundamental partir de los instrumentos básicos de la misión de una institución: sus textos (propios o de terceros), asumidos como expresiones determinadas por su estructura institucional, que se constituye en la producción de proyectos ejecutables. Estos textos deberían ser procesados a través de los instrumentos inductivos y deductivos del método cuyas últimas expresiones, en resumen, son el árbol de problemas/soluciones y el árbol de objetivos y el marco lógico, respectivamente. ${ }^{13}$ (ver recuadro 1)

Si tratamos de ubicar unas delas primeras esencias de estos instrumentos, nos encontramos con el concepto de sistemas de notación. Los sistemas de notación son en el fondo textos nuevos basados en los discursos de origen. Por ello en la primera fase instrumental del método dialógico, "árbol de problemas", el "sistema de notación" protege al "texto" de los "involucrados demanda" de las distorsiones que pueden introducir los "involucrados oferta". En la segunda fase, "marco lógico", el "sistema de notación" también protege el texto original (el delos "involucrados demanda") delas "erosiones textuales" queaparecen en los "textos tradicionales" ${ }^{14}$ de una institución proyectora durante el proceso final de diseño y aprobación. Deesta formaestesistema denotación del discurso y luego texto delosinvolucrados actúa como garantía de una estructura de proyecto, ejecutiva y eval uativa, objetiva y verificable, cuyo origen puede efectivamenteencontrarse en el texto demanda de los beneficiarios. 


\title{
Brian Thomson
}

PROYECTOS, LENGUAJE E INSTITUCIONES PROYECTORAS

\section{4- En estos "textos}

tradicionales" no hay forma de verificar lo que Bertrand Russe llama el carácter dual, verdad/ mentira (Frege), de cualquier texto discursivo. Es dentro del método dialógico que propongo donde se introduce una forma de resolución de esta dualidad, inherente al lenguaje, en la descripción de un proyecto.

\begin{abstract}
que se oponen a un posible proyecto, deben ser registrad os como base para todo el resto del proceso dialógico. En general el $90 \%$ delos proyectos delas instituciones proyectoras evitan estepaso inductivo y proceden directamente a fijar objetivos y crear un fal so marco lógico, porque es exigido formalmente en el proceso de aprobación de un proyecto. En un mundo ideal, la tarea del grupo de participantes comienza por la preparación deuna tabla de involucrados, que seinicia con una lectura cuidad osa del discurso, o texto, delos involucradosen la demanda que defineel problema a resolver. Estos involucrados deben ser identificados y de allí se debe registrar su percepción de los problemas, identificándose también sus intereses (los de un propietario de tierras son diferentes a los de una familia de bajos recursos sin tierra), sus recursos (sus medios para sostener sus intereses, las del propietario serían ejercidas por presiones a nivel político y económico sobrelas autoridades, las dela familia sin tierra sería expresada a través de protestas en el espacio público) y sus mandatos (en un caso acceso a recursos financierosy organizaciones patronales, en el otro la presión política partidaria o gremial, o sus derechos constitucionales y legales). Toda esta información es volcada en la llamada T abla del nvolucrados que se construye con cinco columnas ( grupos involucrados, problemas percibidos, intereses, recursos, y mandatos) y tantas filas como grupos y problemas percibidos existen. Estatabla se debe construir de manera quesea visual menteaccesiblea los participantes y también deuso participativo por lo cual todos los textos se deben escribir en tarjetas pegadas con cinta durex a una pared u otra superficiepara que puedan ser luego usadas en las etapas posteriores del proceso. C on la información identificada en las tarjetas deproblemas percibidos el grupo comienza la construcción del árbol deproblemas. Para ello se debeasegurar primero que cada tarjeta contenga la descripción narrativa deun solo problema. H echo esto, utilizando el principio de causa/efecto los en unciados narrativos de cada "tarjeta problema" son encadenados a través de las rel aciones causa/efecto entrelas mismas. El objetivo del grupo es llegar a establecer relaciones entre las tarjetas, tal que se estructure un «árbol» que tenga las causas más generales en su parteinferior y los efectos más específicos en su partesuperior. Completado el árbol de problemas, el grupo contará con una descripción del universo problema basado en las percepciones delos diversos involucrados. Lo queemergees un mapa queno es resultado de unainterpretación analítica de una disciplina específica. Este mapa, construido en común por el grupo, se constituye en su visión compartida delasituación aresolver. Ello permitiráal grupo comenzar a considerar posibles soluciones al tener en cuentala estructura del problema y deallí empezar a identificar conjuntos y/o subconjuntos del árbol comenzando a pensar en soluciones posibles. Si existeal gún consenso en el grupo sobre cómo encarar posibles soluciones, puede iniciar la tarea de reemplazar las tarjetas problema por tarjetas solución. (continúa en 238 )

Recuadro $\mathbf{1}$ - Cita $\mathbf{1 3}$
El lector debe considerar que esta descripción es muy breve eincompleta y seha incluido sólo a efectos defacilitar lacomprensión demi texto para el que no he usado esta metodología. Por otro lado, el lector debeentender que esta metodologia presuponequeel grupo trabaja en el contexto del método dialógico, en los sistemas de notación utilizados. Estos sistemas de notación en breveresumen son: (i) Árbol de Problemas/Soluciones: esta etapa inductiva dela metodología, es la más importante porque es aquí dondela heteroglosía inicial, los discursos/textos delos beneficiarios, y también delos involucrados
\end{abstract}


(ii) Árbol de Objetivos: el árbol deproblemas juntamente con los datos delas otras cuatro columnas de la tabla de involucrados deriva en la consideración, por parte del grupo, de un árbol de objetivos quese logra, ahora ya con insumos conceptuales de carácter técnico, pero que deben respetar el árbol de problemas heteroglósicos, yaintegrados en una primera homogl osía lógica construida con las percepciones delos involucrados. Los insumos textuales técnicos contribuirán a definir mejor los problemas, agregar más problemas no inicial mentepercibidos por losinvolucradosiniciales, iniciar una consideración estratégica de que problemas pueden ser resueltos y cuales no de acuerdo con los recursos disponibles y las condiciones de recursos y mandatos inicialmente descriptos. En esta etapa es muy importantequeel grupo debata la cuestión dela naturaleza del proyecto. (iii) M arco Lógico: el árbol deobjetivos, acordado con el grupo es la base para la construcción del marco lógico, ya que constituyela base para su primera columna o resumen narrativo, como sevea continuación en brevesíntesis. El marco lógico deun proyecto se presenta como una matriz de cuatro por cuatro. Las columnas suministran la siguienteinformación: (1) Un resumen narrativo dela jerarquía de objetivos. (2) Indicadores (intervalos delogros a alcanzar). (3) M edios deV erificación (fuentes para verificar los indicadores). (4) Supuestos (una manifestación positiva delos riesgos) . Las filas dela matriz presentan información acerca delos objetivos, indicadores, medios deverificación y supuestos en cuatro momentos diferentes en la vida del proyecto. (1) Descripción del fin a ser alcanzado o impacto de desarrollo. (2) Propósito o resultado logrado como consecuencia del uso que los ben eficiarios hayan hecho delos productos entregados por el proyecto. (3) Componentes 0 productos, los bienes y/o servicios generados por las actividades y entregados a los beneficiarios durante el transcurso dela ejecución del proyecto. (4) Actividades requeridas paralos componentes o productos a ser entregados. Para mayor información sobre esta metodología ver la nota número 8.

Las nociones de texto y sistema de notación son entonces dos de los parámetros fundamentales del método dialógico. M enos englobante que la noción de Bahktin, el concepto de lo dialógico que propongo aquí tiene que ver con el sentido práctico que le estoy dando en el quehacer de una institución. En ese sentido se trata de una forma conveniente de describir un método de diálogo lógico: intercambio de discursos, textos, cadenas de significantes, pero dentro de un campo ordenado de reglas para ello, específicamente aplicable a los negocios/transacciones de una institución proyectora que debeelaborar propuestas para ejecutar proyectos de desarrollo adecuados y exitosos.

U na definición adicional que me atrevería a plantear partiría del concepto que describeel prefijo "día", de origen griego que significa, entre otros significados, diversas formas de juntar: el día de diáfano significa "a través de", el de diámetro significa "del otro lado de", el 


\section{Brian Thomson}

PROYECTOS, LENGUAJE E INSTITUCIONES PROYECTORAS

dediálogo significa "intercambio" deideas y propuestas entre personas o grupos, una forma de "juntar y de relacionar opuestos". Estamos, entonces dentro del sentido del significado de "juntar": gente con gente, gente con cosas y cosas con cosas. Desde esta perspectiva y desdeel lenguaje, en los próximos puntos desarrollaré al gunas regl as que deben aplicarse desdeel texto si nuestro objetivo es juntar a un conjunto de dialogadores en torno a un juego lingüístico "proyecto".

En el sentido de "juntar", en vez deordenar cartesianamente, texto se refiereal discurso de los demás, de los otros, o involucrados. Esta definición detexto debeoperar en toda transecta discursiva, desdelas demandas de los involucrad os hasta el discurso técnico de colegas del equipo de proyecto o el discurso de políticas de col egas y agentes de rango superior, en los diversos momentos en que estos ocurren. Todos estos textos deben ser registrados, sin imponerles, ex-ante, un tamiz técnico o depolíticas por parte de quien lo registra, sea este un "involucrado oferta" técnico, o gestionario, o decisorio. El nivel más importantees el del "involucrado" demanda", que es externo a la comunidad lingüística de una institución. A quí, el registro, o captura, del discurso debe ser particularmente respetuoso del sentido original del texto, sea éster egistrado a través de informes técnicos, entrevistas, percepciones manifestadas y/o escritas en una reunión.

El insumo básico de la metodología que aquí se describe está constituido entonces por estos textos que expresan la realidad de los "involucrados demanda", y con ellos intenta construir, sin distorsiones, un "meta-texto demanda", o texto síntesis, que incluya las múltiples descripciones de problemas en una cadena significante ${ }^{15}, 0$ árbol de problemas.

La hipótesis central aquí - valga mi insistencia - es que para poder construir una "respuesta solución" ( o "meta-texto oferta") a un conjunto de problemas, se debe partir de un "metatexto demanda" que simultáneamente incluya todas las percepciones/textos de los involucrados. Ello, porque se transformaron (con este método) en una nueva descripción, integrada y coherente, pasible de manipulación técnica no distorsionante, en la etapa de diseño, ejecución, evaluación, o sea deproducción y uso del "meta-texto oferta". Ello implica que una "estructura solución" debe reproducir los aspectos esenciales de los nodos, relaciones y dinámica de la estructura problema. Pasar no forzadamente dela heteroglosía inicial a una homoglosía consensuada.
15- En lingüística una cadena significante incluye las palabras o significados reconocidos socialmente. Aquí se ha apropiado el término para describir el árbol de problemas como cadena significante. 


\section{CUADERNOU:aAn}

PROYECTOS, LENGUAJE E INSTITUCIONES PROYECTORAS

16- "Variedad requerida" es un concepto de teoría de sistemas. Significa que entre un sistema problema y un sistema solución existe similitud escalar entre la estructura de nodos y relaciones de una, respecto de los nodos y relaciones de la otra.

$\overline{17-\text { Estos conceptos se basan en }}$ un texto periodístico de Sergio Rodríguez (Página 12, Buenos Aires, 07/18/02), inspirado a su vez en un texto de Jacques

19- En sus trabajos, John Holloway desarrolla el concepto del "poder hacer" como esencial a la entidad humana, de allí el concepto de la libertad. Su límite aparece cuando el "poder hacer" se encuentra con el "poder hacer acumulado" o "lo hecho", porque "lo hecho", el producto social, puede ser apropiado por terceros quienes entonces limitan el poder hacer innovativo, porque retiran "lo hecho" de la cadena del "poder hacer" social. Esta es la trampa del llamado "Consenso de Washington".
0 sea, visto desde esta perspectiva se trata de un método que puede generar una base objetiva, en su fase inicial de carácter cualitativo, para desarrollar una operación, que obviamente incluirá, más adelante, los tradicionales métodos de dimensionamiento. Es decir que, en función del "texto demanda", I os "involucrados oferta" generarán un diseño (o "texto oferta", dimensionado) que garantice el logro de los resultados esperados (a través del marco lógico y sus instrumentos complementarios como plan deejecución, indicadores de seguimiento, presupuesto), porque contiene variedad requerida ${ }^{16}$ respecto del "texto demanda" original.

\subsection{El poder implícito en los textos invisibles}

Sin embargo, se deben también tomar en cuenta y descubrir los textos "no escritos", hijos putativos del poder en las instituciones. Aunque tal concepto parezca un contrasentido, estos existen dentro de la institución y se manifiestan en los dichos de todo subordinado. Este, antela duda presumeun discurso o texto desu jefe o supervisor y obra en el sentido de esa presunción. Estos textos invisibles no pueden ser detectados a través de la metodología que aquí propongo, porque son manifestaciones del poder implícito en cualquier relación de dependencia. Lo único que puedo expresar aquí es que existen y deben presumirse como existentes, mientras las relaciones de dependencia se mantengan o refuercen. Ello puede manifestarse por la vía de cambios - a veces sutiles - formulados con un texto visible basado en conceptos de eficiencia y desburocratización, que en la conciencia del sujeto dependientele señal an una reprimenda potencial si no se comporta como espera el texto invisible que está detrás de los conceptos visibles ${ }^{17}$. U na de las maneras de reconocer los contenidos limitantes de estos textos invisibles y también de sus manifestaciones visibles es usar la noción de sujeto deK ant que debeentrar en señal de alarma cuando observamos que un sujeto es considerado un objeto para ser usado ${ }^{18}$ (Ver recuadro 2) . Tal principio, si fuera usado en nuestro mundo neoliberalizado, nos ayudaría a evitar los textos invisibles que acabo de mencionar, como así también los tropos textual es que permiten transformar verdad en otra cosa sin que el sujeto del supuesto mensaje positivo se dé cuenta de la trampa. En nuestro caso, muchas veces ni siquiera el sujeto que afirma el tropo se da cuenta de la trampa que le están haciendo gestar ${ }^{19}$. 


\title{
Brian Thomson
}

PROYECTOS, LENGUAJE E INSTITUCIONES PROYECTORAS

\begin{abstract}
Recuadro 2 - Cita 18
Luventicus Academia de Ciencias, sitio w eb. Kant superó el racional ismo y el empirismo enfocando desde otro punto la cuestión del conocimiento. A este cambio se lo llama "giro copernicano" o "revolución copernicana". Así como Copérnico revolucionó la Astronomía al sostener que no era la Tierra el centro alrededor del cual giraban los cuerpos cel estes sino que era el Sol el astro alrededor del cual giraban la Tierra y todos los planetas del sistema solar, al estudiar la relación objeto-sujeto, que se encuentra a la base del problema gnoseológico, a diferencia de sus predecesores, Kant puso en el centro al sujeto. Él sostenía que los filósofos anteriores (racional istas y empiristas) habían puesto el acento en el objeto deconocimiento: discutían sobrequéconocemos. Unos afirmaban queconocemos ideas por medio de la razón y otros fenómenos a través de los sentidos; pero ambos coincidían en que conocer es reproducir las cosas de un modo pasivo, receptivo, dejándose impresionar por ellas. Kant decía que el centro del problema no era qué conocemos (pregunta por el objeto) sino cómo conocemos (pregunta por el sujeto). Según Kant, el sujeto no encuentra el objeto de conocimiento sino que lo construye, es un sujeto activo. Al tratar la razón práctica (la razón que determina la acción del hombre), Kant también defendía la autonomía del sujeto. Él sostenía que la conciencia moral es el reino de lo quedebeser, en oposición a la $\mathrm{N}$ aturaleza, que es el reino del ser. "Las leyes son, o leyes dela Naturaleza (por las cuales todo sucede), o leves dela libertad (según las cuales todo debesuceder). La ciencia delas primerassellama Física; la de las segundas, Ética". M ientras en la N atural eza impera la necesidad, la causalidad, en la conciencia moral encontramos un imperativo categórico que manda a un sujeto libre, que puede o no obedecer. El imperativo es categórico ( «Debes trabajar») y no hipotético ( «Si quieres sentirte útil, tienes que trabajar»), porque este último depende de una circunstancia (que yo quiera o no sentirme útil). El imperativo moral manda más allá de cualquier circunstancia o situación concreta. Como el hombreno es sólo racional sino también sensible, al actuar no se halla sólo bajo el dominio de la razón sino también del de las inclinaciones. Por eso al hombre el buen obrar se le presenta como un deber, una obligación, una exigencia muchas veces opuesta a sus inclinaciones. $Y$ justamente en la medida en queel hombre actúa por deber, su obrar es moralmentebueno. Porqueel valor moral de una acción no depende de lo quese pretenda lograr con ella sino del principio o máxima por el cual se la realiza. Kant formuló el imperativo categórico de diversas maneras (no opuestas, sino complementarias). De ellas cabe destacar dos: «N o obres nunca sino de manera que puedas querer que la máxima que rigetu obrar se transforme en ley universal». ( $N$ o busques privilegios, ley privada, ni excepciones. Piensa qué pasaría si todos obrasen del mismo modo. No hagas lo que no te gustaría que otros hicieran.) «Obra de tal modo que uses a la humanidad - tanto en tu propia persona como en la persona de cualquier otro- siempre como un fin, nunca como un medio."
\end{abstract}




\section{CUADERNO}

PROYECTOS, LENGUAJE E INSTITUCIONES PROYECTORAS

20- Ver Andrew W. Crosby The Measure of Reality:

Quantification and Western Society, 1250 - 1600, Cambridge University Press, 1997.

21- El desfase, entre el Calendario Juliano y la realidad solar, era tan grande en 1582 , que llevó al Papa Gregorio XIII, asesorado por un cuerpo de expertos, a proclamar que el jueves 4 de octubre sería seguido por el viernes 15 de octubre. Nueva base del sistema que sobrevive hoy.

\subsection{El diseño dialógico como sistema de notación}

Cambiar «un sistema de notación" es una transformación profunda de cómo una institución manifiesta sus expresiones discursivas y textual es. Está muy lejos de ser, como siempre lo consideraron al gunos profesionales y gerentes dela institución proyectora en la cual trabajé, solamente una cosa trivial, sólo otra forma de escribir. En realidad si tal tipo de cambio se asumiera profesional einstitucional mente generaría un cambio no solamenteen los procesos de producción de proyectos ejecutables sino también en sus contenidos. Para reforzar este argumento sólo necesitamos considerar la importancia de los ejemplos que siguen.

U na rápida revisión dela historia de los principios del desarrollo científico/técnico europeo, entre 900 y 1600, muestra que los sistemas de notación son en realidad las hermanas y madrinas de la invención. Algunos ejemplos demuestran esto con prístina claridad ${ }^{20}$, pensemos solamente en la significación de los siguientes casos:

* La tabla de contar y los números Indo-A rábigos, llevados a Europa, desde España, por el frailefrancés, Gerbert (quien luego sería el Papa Silvestre II).

* Circa 1200, Stephen Langdon (quien luego sería el arzobispo de Canterbury) elaboró un sistema para la clasificación por textos y versos de los libros de la Biblia. Sistema queluego los escolásticos consolidarían en su método declasificación alfanumérico para sus manuales y diccionarios de material es para sermones (que aún hoy usamos para nuestros documentos). Este sistema permitió organizar grandes masas de información, defácil búsqueda y uso. Con el tiempo, se desarrolló la "tabla analítica de contenidos" para el acceso rápido a textos, sistema de notación que griegos y romanos nunca desarrollaron.

* Lapreocupación por la medición del tiempo, inicialmentepara asegurar la correlación entre festividades religiosas y los ciclos astronómicos ${ }^{21}$, llevó al desarrollo de un medio de verificación para la medida diaria del tiempo, el reloj cuyo elemento fundamental de medida fue el "escape" ( pieza que alternativamente se separa y se junta con la cremallera de la rueda, regulando su movimiento) el cual llevó a que se tomara su movimiento como la unidad mínima de tiempo medible. Otra forma de notación incipiente. 


\section{Brian Thomson}

PROYECTOS, LENGUAJE E INSTITUCIONES PROYECTORAS

* El redescubrimiento de la Geographia de Ptolomeo en 1400, permitió asignarle al espacio un método de cuantificación parecido a lo que en relación con el tiempo había contribuido el "escape de rel oj". En efecto, estedocumento permitió cuantificar el espacio, sometiéndolo a un sistema de coordenadas, principio madre de la cartografía que permitió a los marinos navegar mares, llegar a sus destinos y volver a sus puertos de origen. ${ }^{22}$

* La introducción de los números Indo-A rábigos no eliminó el problema de cómo efectuar operaciones con ellos. H asta el propio Fibonacci, a mediados del siglo XIII, se vio sometido a la necesidad de combinar números con palabras para describir operaciones del tipo "2 más 2 es igual a 4". En Italia en el siglo XV comenzaron a reemplazar la pal abra "más" por una " $p$ " con una raya encima y "menos" con una "m" similar. La confusión no seresolvió, sobretodo en operaciones algebraicas quetambién usaban letras. Las notaciones,,+- , etc., no aparecieron hasta fines del siglo XV en Alemania $(t,-)$ e Inglaterra $(\Rightarrow$. Simples notaciones nuevas que permitieron el desarrollo ulterior delas matemáticas.

Podría seguir dando ejemplos, según el libro de Crosby, tales como la invención de la ubicación del 0 (cero) para designar órdenes de magnitud por decenas, centenas, etc., la creación de escritura en letra cursiva y la contabilidad de doble entrada, pero creo que los ejemplos que hemos visto, dejan bien en claro la importancia delos sistemas de notación en el desarrollo de mejores formas de ordenar, manipular y registrar información de manera que facilite la generación de descripciones de la realidad para permitir su mejor comprensión y manejo.

Q ué es sino, precisamente, esto lo que queremos lograr cuando describimos un proyecto: facilitar su ejecución con un éxito que a su vez sea evaluable. Si un mejor sistema de notación contribuye a este fin, más bien convendría usarlo. El método de diseño dialógico que propongo no es un antojo o extravagancia metodológica: es un nuevo sistema de transacción y notación de utilidad en una comunidad lingüística que contribuye a sistematizar de una manera simpley práctica todas las piezas del rompecabez as de diseño, ejecución y evaluación de un proyecto. Ciertamenteno es el único instrumento, pero sirve para poner orden entre los diversos instrumentos que se utilizan, manteniendo su
22- Esta definición es casi una metáfora para la necesidad que tenemos de poner en su lugar a cada elemento (en realidad se trata de juicios gramaticales) que contribuye a la ejecución exitosa de un proyecto. No parece poca cosa dada la complejidad que se maneja en la ejecución de un proyecto. A veces se la llama trivialidad ipero qué trivialidad! 
preeminencia entre ellos. No es un método más, como se dijo en muchas oportunidades desde al gún paraninfo técnico o gestionario de las instituciones proyectoras.

\section{ALGUNASREGLASPARA UNA ARQUITECTURA DEL LENGUAJE}

Si insinuéal comienzo los límites cartesianos del método de la geometría descriptiva ahora propongo un conjunto de alertas lingüísticas que nos permitan avanzar en una dimensión nueva del método arquitectónico que nos permita pasar del edificio a la producción de espacios sociales y nos permita orientarnos en la jungla creada por las instituciones proyectoras, manteniendo a salvo los principios dialógicos que he considerado hasta aquí en este trabajo.

\subsection{Filosofía y gramática}

W ittgenstein sostenía que los mayores problemas de la filosofía, sobre todo los de verdad y falsedad, y de coherencia entre lo dicho y su manifestación fenoménica, se podían resolver en las estructuras gramaticales de nuestras diversas postulaciones discursivas y textuales. Para los instrumentos del método de diseño dialógico estees entonces un tema importante. Sin embargo, los creadores del método del marco lógico nunca definieron de qué lógica estaban hablando, lo cual Ilevó a una falta de sustentación teórica que permitió que en las instituciones proyectoras el métod o se aplicara de manera mecanicista desdeuna práctica sustentada en la autoridad. Por ello, es usual en las instituciones proyectoras que en un taller de marco lógico ante la pregunta "iporqué tal cosa es así?" la respuesta usual es "iporque en marco lógico es así!". Por ello si queremos entender mejor sus cualidades, aplicaciones y limitaciones, y queremos asegurar su uso en un medio escéptico constituido por profesionales "formados" en otros métodos, debemos incursionar en el tema dela lógica que sustenta el método.

Personalmente no tengo formación en este campo y por ello no estoy calificado para tratar el tema en profundidad, pero trataré de evidenciar la relación con nuestro tema de aquellos principios lógicos gramaticales que todos hemos visto en nuestros estudios secundarios y universitarios, y que aplicamos cotidianamente de manera intuitiva en nuestro que- 


\section{Brian Thomson}

PROYECTOS, LENGUAJE E INSTITUCIONES PROYECTORAS

hacer profesional. Algunos de estos principios tienen aplicación en la etapa inductiva 0 de construcción del árbol de problemas dialógico, otras en la etapa deductiva o de marco dialógico, y otros son de aplicación a cualquier etapa, pero todas tienen en común la conexión entre la lógica gramatical y las cadenas significantes verbales y/o escritas, a través de las cuales nos comunicamos, compartimos ideas y llegamos a determinaciones. Esta lógica sirve para reforzar entonces el concepto dialógico que propongo para esta metodol ogía. Los principios que mencionaré a continuación incluyen: la mayéutica socrática; los modos de ser de los objetos; principios lógicos gramaticales generales; conceptos de inducción y deducción; reglas semánticas; y, tropos (ver 5.7).

\subsection{M ayéutica Socrática}

Un buen punto de partida para construir una arquitectura del lenguaje es recordar el método mayéutico de Sócrates. H oy lo conocemos como las "siete preguntas de Toyota", olvidando queen realidad esas preguntas vienen dela G recia Antigua. Según Platón, Sócrates sostenía queel sujeto tenía un saber que podría ser alcanzable por la indagación sistemática. En el método dialógico no hacemos otra cosa que aplicar este simple principio de la mayéutica, cuando en un grupo nos preguntamos repetidas veces por quédefinimos un fin, propósito, producto, o insumo detal manera y no deotra.

Esta sucesión de preguntas y repreguntas tienen, entonces, la función de asegurar que el concepto sea por lo menos más claro. Por ejemplo, si refiriéndoseal propósito de un proyecto un colega mencionara una "inspectoría de proyectos", yo le preguntaría quées eso. Antesu respuesta de que "es la revisión auditada de los procesos de licitaciones, compras y contrataciones de proyectos en ejecución", le pediría que me explique qué cambio se produce ( en un proceso, institución, persona, etc.) como resultado de haberse efectuado esta revisión. La respuesta podría ser que "mejora el uso derecursos públicos". Esta respuesta sería la correcta definición del propósito deun proyecto. A plicando la pregunta y repregunta se puede pasar de una fal sa definición (un malapropismo - voz de aplicación impropia, 0 "quien tieneboca seequivoca"- un título sin contenido, un objeto sin cadena significante, es decir sin estructura de referencia entre cosas) a una correcta definición, un resultado que expresala transformación de una situación indeseable en otra futura deseable. 


\section{CUADERNO}

PROYECTOS, LENGUAJE E INSTITUCIONES PROYECTORAS

23- Pueden expresarse diferentes modos de ser del mismo objeto.

Por ejemplo, el mismo objeto IVA (Impuesto al Valor Agregado) se expresa como un modo de ser

visto como estudio de reforma, como otro modo de ser visto como propuesta de ley, como otro modo de ser visto como cuerpo de normas administrativas, y como otro visto como efectos sociales $y$ económicos producidos por la aplicación de ese cuerpo de normas.

24- Por este término se implican las descripciones de proyectos que usan terminología de la tabla de inversiones por línea de gastos.

\subsection{M odos de ser de los objetos}

En este desarrollo también es fundamental el concepto del modo de ser de los objetos que se incluyen en los juicios deductivos. Si digo "de A deduzco B", debo primero preguntarme por los modos de ser de A y B. ${ }^{23}$ Si tomamos un caso típico de los documentos de una institución proyectora y nos preguntamos por las descripciones que incluyen, usualmente nos encontraremos con el problema de diferentes modos de ser. Por ejemplo, el modo de ser de una tabla contable de los insumos que se van a financiar para ejecutar un proyecto es diferente al modo de ser de una descripción de cómo voy a usarlos para construir la solución. Si A es la tradicional descripción de insumos y B es el proyecto terminado y exitoso, es simple concluir que "de A no deduzco B". Otros ejemplos serían: si digo al describir los objetivos de un proyecto: "C apacitación y Desarrollo Institucional" estoy describiendo un objeto cuyo modo de ser - aunque legítimo en el contexto contable- no me dice nada acerca de lo que va a pasar como consecuencia de aplicar esa capacitación, que es otro modo de ser, real y utilizado por al gún beneficiario. Es obvio que aquí de $A$ no deduzco $B$. Sólo si describo el proyecto en términos de los efectos a lograr, por ejemplo "productores algodoneros mejoran sus sistemas de producción" de A (la descripción) podré deducir B (el impacto de desarrollo logrado), porque el modo de ser de la descripción es consistente con el modo de ser del efecto de su aplicación.

El tema del modo de ser de los objetos también nos ayuda, si consideramos los contenidos de los juicios narrativos a través de sus indicadores. En los documentos de las instituciones proyectoras, la descripción narrativa en juicios contables (V g. "C apacitación y Desarrollo Institucional") termina con indicadores que describen bienes y servicios a contratar, y las actividades para ello. Por el contrario, la descripción en términos de efectos a lograr tiene un correlato en indicadores del tipo: "pulverizaciones reducidas de $x$ a y en $z$ años; plantas de al godón por hectárea pasan de 30.000 a 60.000 con y calidad de capullo, en $z$ años.

En general, observada esta situación en una institución proyectora se le señala al impertinente indagador, otra vez, que es un tema trivial porque sólo se trata de cómo escribimos. Garrafal error, que aún persiste, sustentado por macros ( patrones informáticos para elaborar documentos) que padecen, a su vez, de un modo de ser contable $e^{24}$ de descripción. 


\section{Brian Thomson}

PROYECTOS, LENGUAJE E INSTITUCIONES PROYECTORAS

Esta, como si fuera poco, es la diferencia entre decir "compre x número de ladrillos rojos" y decir "construir una pared"..$^{25}$ Esta argumentación no pretende concluir que una esta mal y la otra esta bien. A mbas son lógicas y gramatical mente correctas. La cuestión es ¿cuál me permite ejecutar un proyecto? ¿C uál se refiere al modo de ser "proyecto ejecutado"? Sólo la que describe el proceso de ejecución, no la que describe la lista de materiales. N o hay dilema aquí desde el punto de vista operativo. Se pueden usar las dos descripciones, una para el discurso interno de aprobación, otro para el discurso externo de ejecución. Pero, lamentablemente y frecuentemente la del discurso externo desaparece y queda la descripción contable (otro recesivo genético cartesiano) que no describe la necesaria arquitectura ejecutiva. Este no es un tema trivial y lo que lo transparenta es uno de los primeros principios de la lógica: sólo se pueden efectuar deducciones afirmativas entre juicios si los modos de ser de sus objetos están implicados entre sí, en unión (finalidad) 0 en uniformidad (en el obrar).

Si A es la descripción de un proyecto y B es el mismo proyecto ejecutado, entonces:

Si A es una descripción contable, no se deduce B. Si A es una descripción ejecutiva, se deduce B. Claro, la validez de esta deducción está sujeta al principio de 'ceteris paribus' y no supone la heroica intervención de ejecutores y de funcionarios de los países beneficiarios que tratan de traducir la descripción contable en una descripción ejecutiva: o sea ponerlejuicio deductivo a algo que no lo tiene.

Tampoco sirve el intento de camuflar diferentes modos de ser mediante artilugios descriptivos (malapropismos). En este sentido el método dialógico es un transparentador de artilugios, puesto que cuando se intenta aplicarlos utilizando las descripciones contables de los documentos de la institución proyectora, las limitaciones de éstas se hacen rápidamente evidentes.

\subsection{Principios lógicos gramaticales ${ }^{26}$}

Otros elementos lógicos, de ordenamiento narrativo, aplicables en nuestra metodología dialógica son: el principio deidentidad ( $A$ es $A$ ), el principio decontradicción ( $A$ es diferentedeno A), el princi pio deexclusióndetercero ( $A$ es $A$ o no es A), y el princi pio decausa/efecto (si A entonces B). Este
25- Ver Wittgenstein, Ludwig "Philosophical Investigations"; Third Edition, Prentice Hall, 1958; páginas 3 a 10.

26- Por ejemplo según la versión dialéctica hegeliana

(Enciclopedia Larousse, Tomo Quinto, p.235, “Contradicción", Versión Española, 1967), el principio de contradicción es la ley que preside su sistema lógico, que concibe lo real como sistema de sucesivos momentos opuestos, inexplicables según el principio de identidad. Ver también: José M. Rubert Candau, "Diccionario Manual de Filosofía”, pp.392 a 394, Editorial Bibliográfica Española, Madrid, 1946. 


\section{CUADERNO}

PROYECTOS, LENGUAJE E INSTITUCIONES PROYECTORAS

27- Para el lector crítico, debo aclarar que estoy tomando los principios de la lógica

gramatical en su acepción más

sencilla. En este sentido hay

autores mas recientes que

rechazan la validez del principio

de exclusión de tercero en base a una noción, no inexacta en algunos universos, de

polivalencia lógica. Sin embargo es mi opinión que si partimos del juego de palabras proyecto, los principios originarios de la lógica gramatical son aplicables. último, dentro del campo de la lógica empírica o material (según J.S. M ill System of Logic, 1843) en su expresión gramatical, es el principio queadquiere función determinante en el campo del método de diseño dialógico.

¿Por qué asumimos esta prioridad del principio decausa/efecto (si A entonces B)? Porque la misión de una institución proyectora es generar y ejecutar proyectos, 0 sea asegurar el cumplimiento de secuencias o cadenas de causa/efecto para garantizar la relación medio/fin, o sea inversión/resultado, consistente con los postulados de la lógica empírica y su expresión gramatical. U na institución proyectora ejecutiva es una institución dedicada a diseñar cadenas de medios/fines que mejoren/modifiquen las problemáticas implícitas en las cadenas de causas/efectos indeseables originales.

El principio deidentidad ( $A$ es $A, A$ no es $B$ ) seaplica en el método dialógico (en el instrumento marco dialógico) a la relación entre narrativa, indicador y medio de verificación. En el instrumento árbol de problemas dialógico se aplica el hecho de que no puede haber dos problemas en una misma secuencia narrativa. Por ejemplo, "el agua es poca ( $A$ ) y es demala calidad ( $B$ ), deben ser separadas, cada una con su identidad, $A$ A y $B=B$ ".

El principio decontradicción (A no puedeser A y no ser A al mismo tiempo) seaplica, juntamente con el decausa/efecto, a la relación vertical entreactividades/productos, productos/propósito o resultado, propósito/fin o impacto de desarrollo, etc. También se aplican al árbol de problemas dialógico en la medida que una percepción narrativa no puede incluir un problema y su opuesto ( por ejemplo "no tenemos agua pero el agua es buena") y por otro lado narrativas causales entre sí no pueden estar en el mismo nivel causal del árbol.

El principio de exclusión detercero ( $\mathrm{A}$ o es $\mathrm{A}$, o no es $\mathrm{A}$, pero no puede ser una tercera cosa, o sea B) se aplica sobre todo en combinación con el de causa/efecto en el hecho de que si A sólo es $A$ y $B$ sólo es $B$, y $A$ es causa de $B$, no puede haber un $C$ que sea consecuencia de $A$. Este caso se ve claramente en la relación causal productos/componentes $A 1, A 2$, An (estos desde el punto de vista causal, relativo al propósito, son todos A's) a propósito B, donde queda excluido un propósito $\mathrm{C}$. 0 sea que un proyecto sólo puedetener un propósito. ${ }^{27}$ 


\section{Brian Thomson}

PROYECTOS, LENGUAJE E INSTITUCIONES PROYECTORAS

\subsection{Inducción ${ }^{28}$ y deducción ${ }^{29}$ (Ver Recuadro 3)}

Cabe también una referencia a los conceptos de la inducción y la deducción lógicas, a las cuales nos hemos referido como los dos Tex tos de todo método referido al conocer y el actuar, como el método dialógico dedicado a la relación inversión/resultado. Según la ya citada obra clásica de J.S. M ill, la inducción es el método fundamental y base de la deducción. ${ }^{30}$ Esta posición enfatiza aun más la importancia de aplicar siempre el método inductivo dialógico ${ }^{31}$ como se lo propone aquí (árbol dialógico) antes de intentar la aplicación del método deductivo tradicional al diseño de proyectos. Según M ill la inducción consiste en aislar las relaciones de causalidad, que él define como única ley universal (todo efecto

\footnotetext{
Recuadro 3 - Cita 28

JoséM . R ubert C andau, “Diccionario M anual deFilosofía”, Editorial BibliográficaEspañola, M adrid, 1946, pags.355-359. D ebetomarse, también, nota de que muchos tratadistas consideran lainducción un caso especial de los principios de la deducción. Si este fuera el caso del lector, lo libero de toda responsabilidad en el tema, pues en mi opinión en su aplicación en el método dialógico podrían también hablar de "deducción ex-ante" como reemplazo dela palabra inducción y de "deducción ex-post" en reemplazo de lo que aquí llamo deducción. M e refiero, en el contexto de la práctica que propongo dialógica, a lo que en lógica sedenomina inducción real (y no metafísica). La inducción no es posiblesin legitimidad conceptual, y esa parte del conocimiento que setenga del comportamiento del mundo real. Estepuedeser erudito (técnico), o no-erudito (lego). Pero en ambos casos la inducción real debecumplir dos reglas basadas en la experiencia del mundo: queexista unión entrehechos reales, por ejemplo: una cañería esta en unión con el fluido que conduce, o bien adquirir un bien, digamos agua potable esta en unión con un precio (en lógica esta es la ley de finalidad entre ciertos objetos reales); 0, que exista uniformidad en la producción delos hechos, por ejemplo sabemos quesin agua los cultivos sufren o que sin presupuesto no puede haber inversión (en lógica esta es la ley de uniformidad en el obrar entre ciertos objetos reales).

Estas dos leyes nos ayudan a construir las cadenas de causa/efecto entrehechos y/u objetos reales. Pero aquí cabeaclarar que para poder construir estas cadenas inicialmentedebeevitarsequelas descripciones delos hechos/objetos reales no sean del tipo $A=a^{\prime}+a^{\prime \prime}+a^{\prime \prime \prime}$, etc. ya queen ese caso no sabríamos cual delos contenidos de A produce el efecto B. Y si B también es del tipo B =b' +b" +b"', etc., no sabríamos cuál de los contenidos de $A$ afecta a cual delos contenidos deB. Por ello, como ya hemos visto a lo largo de estetrabajo, los registros de los enunciados delos involucrados no deben contener más deun objeto, porquesi no, no será posibleestablecer cadenas claras designificación dela problemática a encarar. De manera similar, si cuando describimos un proyecto, parasu aprobación/ejecución, lo hacemos utilizando categorías que en realidad son conjuntos de hechos u objetos, no será posible establecer la cadena medios/fines necesaria para contribuir a una buena ejecución y evaluación.
}

29- En realidad la deducción no es, ni más ni menos, lo que se hace cuando efectuadas ciertas observaciones problemáticas, sustentadas en un proceso de inducción, aplicamos, a las inducidas reglas materiales de causa/efecto (expresadas ya en un árbol de objetivos), un sistema de reglas técnicas deductivas para diseñar la solución.

El problema que emerge aquí es la posible falta de ajuste entre las reglas de causalidad del problema y las reglas deductivas técnicas. La disyunción emergente llevará al inevitable fracaso de la propuesta. Entonces, la cuestión fundamental a resolver es lograr isomorfía y variedad requerida entre ambos sistemas deductivos. Un ejemplo extremo de esto sería aplicar un análisis económico de precios de mercado a la voluntad de pago por un servicio, de una población que no tiene ni trabajo ni ingresos.

30- Muchos autores modernos argumentan que la inducción es un caso particular de deducción. Nuevamente en el universo del proyecto, asumo que la inducción es un procedimiento analítico fundado en sus propias prácticas.

31- Siempre combinado, obviamente, con los otros métodos de dimensionamiento, en el ámbito de diagnóstico y análisis, propios del diseño de proyectos. 


\section{CUADERNO}

PROYECTOS, LENGUAJE E INSTITUCIONES PROYECTORAS

tiene un antecedente invariable). La deducción - en nuestro caso el marco dialógicose funda en la inducción y se basa en los ya mencionados principios de la lógica gramatical.

Como ya dijera, esta argumentación se funda en visiones prácticas de la aplicación de diversas reglas en el método dialógico. Por ello, no entraré en el debate más que centenario entre inducción y deducción, en términos de si una incluye a la otra, o no. Para mí lo importante es el momento en el cual se están aplicando los principios metodológicos aquí expuestos. En este texto parto de la base de que en la fase de conocimiento de la natural eza deun problema se está inducien do y que en la fase de generar propuestas se está deduciendo.

También cabe aclarar cuál es el tipo de inducción y/o deducción al cual me refiero aquí. Como el método es iterativo el proceso de inducción pasa de un contenido inicialmente cualitativo (la naturaleza de problemas y soluciones) a un contenido crecientemente cuantitativo (la dimensión de problemas y soluciones). El método dialógico es aplicable en las dos fases, pero los métodos analíticos de las disciplinas específicas son malos consejeros en la dimensión cualitativa, aunque devienen esenciales cuando nos introducimos en la dimensión cuantitativa. Por ello el primer árbol de problemas descriptor de un sistema de problemas se debe basar en los dichos y/o enunciados de los diversos involucrados, y el proceso de inducción que buscará encontrar una cadena de significaciones será fundamentalmente no-dimensional. Pero cuando queremos precisar la naturaleza del problema, comenzaremos a dimensionar las líneas de causa/efecto del árbol, incrementando el nivel de realidad de nuestras observaciones. A demás, la teoría de la lógica nos dice que "toda inducción es una observación incompleta", por lo cual hay quedeterminar cuándo tenemos suficientes observaciones - problema fundamental del costeo depreparación de proyectos- .

\subsection{R eglas semánticas}

Las reglas semánticas se diferencian de las sintácticas en que las primeras se refieren a la cuestión de la verdad/falsedad de los dichos, mientras las segundas se refieren a la corrección en el uso de los significantes, o palabras. Puede crearse una oración sintácticamente correcta pero semánticamente incorrecta. Las reglas semánticas que mencionaré aquí también parecerán triviales, pero si las aplicamos a nuestros escritos típicos cambiaremos de 


\section{Brian Thomson}

PROYECTOS, LENGUAJE E INSTITUCIONES PROYECTORAS

opinión rápidamente, veremos que nuestras descripciones de mando o ejecutivas requieren una semántica diferentea nuestras descripciones de relato o explicativas.

El primer principio es recordar que el paradigma del marco dialógico es una cadena narrativa de causa/efecto deductivo hipotético de las relaciones entre actividades, sus productos, el resultado del uso que el beneficiario hace de esos productos, y el impacto en la sociedad de los beneficios resultantes. Ello tiene una inmediata implicancia semántica en que toda narrativa de componentes, propósitos y fines de proyectos, debe ser expresada como al go ya logrado, lo cual implica el uso del participio depasado en las formas verbales (contratado, ejecutado, etc.). La excepción a lo hipotético en su propio nivel son las actividades. Estas se consideran procesos controlables por el ejecutor, luego se expresan verbalmente en el infinitivo (contratar) o el gerundio (contratando), o en verbossubstantivados (contratación).

En cada nivel narrativo se debe respetar el modo de ser de cada nivel. Un propósito 0 resultado expresa un cambio en las condiciones de la entidad beneficiada por el uso de los productos o componentes, luego no puede ser expresado ni por algo que se espera que pase, ni por una expresión semántica que sólo se refiera a la producción de un objeto (confundir componente con propósito) en sí, o sea un modo de ser diferente. Es como confundir "capacitación de maestros" (actividad), con "maestros capacitados" (producto), con "maestros enseñan mejor" (propósito, o resultado a nivel de un grupo humano).

En el sentido dela regla precedente toda descripción narrativa debeconstituirsecon oraciones, o sea que determinan al go que pasa con un objeto a través de una cópula. Decir, por ejemplo, como frecuentemente ocurre "fortal ecimiento institucional" es casi igual a no decir nada en nuestra problemática porque comienza a actuar más como signo (el "PARE" de una señal de tránsito) que como una palabra. En este caso es solamente una palabra compuesta (en este caso un sustantivo), y las palabras, simples o compuestas, sin una cadena de otros significantes no significan nada desde el punto de vista semántico. Es igual que decir la palabra leche, que sola no significa nada. También es sólo un signo no un significado. Basta probar su uso con un miembro de la familia en la cocina, para probar esta tesis. Las preguntas posibles del interlocutor serian: ¿Leche fría? ¿Leche caliente? ¿Leche fría para tomar ahora? ¿Leche caliente para hacer chocolate? Lo mismo ocurre cuando definiendo al gún producto o componente de un proyecto digo "fortalecimiento institucional", 
"equipamiento", "capacitación". Sintácticamente en el contexto de una tabla de costos, me permiten explicar cuántos kilos de cada una quiero comprar, pero no me dicen cómo hago el puchero, o el guiso, o la tarta de manzanas. Esto sí que parece bastante simple. Se podría diseminar un memo ejecutivo que dijera "describan los productos y efectos de un proyecto con oraciones". N o hace falta el marco dialógico para esto, pero sí hace falta para no tener que estar dando instrucciones similares repetidamente. ¿Por qué? ¡Porque es un sistema denotación!

¡Q uién hubiera dicho que una mera conjunción puede causar graves problemas de descripción ejecutiva precisa, tan necesaria para ejecutar un proyecto! Las conjunciones coordinantes que designan una relación explicativa entre oraciones ("me interesa el cine, pero coordinante copulativa - prefiero el teatro"), no son tan peligrosas para la descripción ejecutiva. Pero las conjunciones subordinantes ("saldré de compras si - subordinante condicional- me llega el dinero") sí son peligrosas porque describen más de un objetivo, sea esta una actividad, un componente, un propósito, etc., creando confusión entre niveles y entre indicadores. También podemos tener conjunciones causales como "luego". N ótese que en el segundo caso mencionado, la conjunción subordinante describe un supuesto. Ejemplos típicos de conjunción coordinante peligrosa es cuando se dice de un propósito "reducción de costos de transporte e integración regional logrados". Aquí se está hablando de dos objetivos diferentes; uno es consecuencia de otro, "integración" es consecuencia de "reducción de costos". Alguien podría decir "entonces lo escribo reducción de costos de transporte por lo tanto se logra la integración regional". Cierto que esto es semánticamente más correcto que la descripción anterior, pero por ello se muestra más precisamente una relación de causa/efecto, por lo tanto, se trata de dos niveles diferentes de logro de objetivos. Debe recordarse que en el concepto de conjunción se incluyen las Ilamadas locuciones conjuntivas, que se forman con dos o más el ementos gramatical es vía preposiciones y ciertas formas adverbiales, en buena parte de las cuales participa la partícula que: p.ej. porque, conque, para que, etc. El último de los mencionados es típico de una conjunción que reemplaza lo que sería una preposición, para.

El uso de preposiciones también es de cuidar porque, como las conjunciones, actúan gramaticalmente como vínculos en las oraciones, y el vínculo entre juicios es uno de los fundamentos del marco dialógico. Esto también es claro ya que la preposición es defini- 


\section{Brian Thomson}

PROYECTOS, LENGUAJE E INSTITUCIONES PROYECTORAS

da como "partícula de relación subordinante". Por ello convierte en complemento a cualquier sustantivo. Si digo "Ios caminos deben ser transitables para asegurar la integración regional", estoy relacionand o subordinadamente dos sustantivos (objetos) entre dos oraciones que forman una oración compleja. De hecho, entonces, estoy hablando de dos cosas diferentes "caminos2 e "integración regional" que deben ser expresadas en dos niveles diferentes de un marco dialógico si quiero instalar la claridad ejecutiva que necesito para invertir recursos financieros. ${ }^{32}$

\subsection{Los tropos y otros errores a evitar en el lenguaje de diseño de proyectos ${ }^{33}$}

Finalmente, en este camino no convencional, elegido para incursionar en la dimensión narrativa del tema del marco dialógico, nos queda otra vertiente. La de cuidarnos de los posibles trucos verbales constituidos por los tropos o "empleo de las palabras en sentido distinto del que propiamente les corresponde, pero que tiene con este al guna conexión, correspondencia o semejanza".

Los tipos de tropos son tres: la sinécdoque, la metonimia y la metáfora, las cuales pueden crear trampas narrativas no detectables, que en realidad son formas de traspasarse de modos de ser sin que se note y de generar formas sintácticamente correctas que pueden ser semánticamente incorrectas. Es claro que en literatura, particularmente en la poesía, los tropos son la esencia de la creación de nuevos significados y conexiones imaginarias entre realidades. Pero, el financiamiento/ejecución de un proyecto no tiene la estructura gramatical de una poesía.

* Sinécdoque: tropo que consiste en designar un todo con el nombre de una de sus partes, o viceversa, una cosa con el de la materia de que está formada, etc.: $\mathrm{Vg}$.: cuarenta velas por cuarenta naves; el pan por toda clase de alimento; el bronce por el cañón o la campana.

Ejemplos para nosotros serían: (i) hablar del 'objetivo de un proyecto', cuando en realidad se trata de 'varios objetivos en el mismo proyecto'; (ii) decir 'la competitividad de la economía', en vez de precisar 'la competitividad de los secto-
32- Siguiendo aquel axioma homérico que decía "Tened cuidado de los griegos que traen presentes", recordemos las preposiciones: a, ante, bajo, cabe, con, contra, de, desde, en, entre, hacia, hasta, para, por, según, sin, so, sobre, tras, cuando estamos redactando objetivos.

33- En todas estas referencias e autor ha usado las definiciones del Diccionario de la Real Academia Española

(Decimonovena Edición) y/o referencias a la Enciclopedia Larousse, 20 Volúmenes, Buenos Aires, 1967. 
res exportadores'.

* M etonimia: tropo que consiste en designar una cosa con el nombre de otra, tomando el efecto por la causa o viceversa, el signo por la cosa significada, V g.: las canas por la vejez, el laurel por la gloria. Ejemplos para nosotros serían: (i) decir cliente por paciente en un hospital; (ii) decir 'transacciones internas' por 'colaboración interdepartamental' dentro de una institución; (iii) decir 'alternativas educativas' por 'educación segmentada entre grupos económicos'.

* Metáfora: tropo que consiste en trasladar el sentido recto de las voces en otro figurado, V g.: las perlas del rocío, la primavera de la vida. El sentido figurado enmascara la significación de la palabra dándole otra diferente.

Ejemplos para nosotros serían: (i) decir 'la transparencia del mercado' por 'oportunidades privilegiadas'; (ii) decir 'empleabilidad del trabajador' o 'transparentar el mercado laboral' por 'reducción de costos laborales'; (iii) decir 'ajuste estructural' por 'cambiar las relaciones sociales de producción a favor de la inversión'.

Lo fundamental de los tropos es que permiten deslizar contenidos diferentes a los reales, a través de cadenas significativas aparentemente reales, pero en efecto figuradas.

Como ya señalara, si bien en el mundo del arte, de la narrativa literaria y de la poesía son instrumentos fundamental es de la creación artística, en el campo del discurso proyectual, nos Il evan, inevitablemente, por malos caminos. La sinécdoque y la metonimia son bastante frecuentes en escalas detalladas de proyectos. La metáfora generalmente aparece en el ámbito de políticas, forma viral en la cual invade generalmentela narración denotativa delos proyectos.

También debemos reconocer y evitar los malapropismos (voces de aplicación impropia), los paralogismos (falsos argumentos) y las polisemias (la inclusión de más de un significado en un texto). Todas estas prácticas - parafraseando a Karl Kraus- Ilevan a ahogar el significado de adjetivos, verbos y adverbios en un mar de objetos o sustantivos, vacíos de contenidos activos; 0 sea, vacíos de proyecto. 